\title{
The Association of Emotional Intelligence and Job Satisfaction in Operating Room Technologists
}

\author{
Payman Rezagholi ${ }^{1}$, Pariya Foroughi ${ }^{2}$, Asra Foroughi $^{3}$, Sirous Shahsawari ${ }^{4}$
}

\begin{abstract}
Background \& Aims: Occupational satisfaction is one of the most important and effective factors for the increase in organizational productivity. In addition, emotional intelligence is a series of skills that increase a person's ability to face environmental pressures. Given the effect of emotional intelligence on individual psychological health, and with regard to the role of occupational satisfaction on the quality of services provided by operating room technicians, this study aimed to determine the relationship between emotional intelligence and occupational satisfaction in operating room technicians.

Materials \& Methods: This cross-sectional, descriptive, and analytical study was performed on all operating room technicians in hospitals of Sanandaj, Iran $(n=110)$ were selected by census sampling in 2016, 10 of whom were excluded from the research due to a work experience less than one year. The inclusion criteria were a minimum work experience of one year, lack of chronic psychological diseases, lack of drug use, and no severe crises such as the death of first-degree family members, divorce, bankruptcy, and loss of property in the last six months. Data were collected using a demographic characteristics questionnaire (e.g., gender, marital status, education, income level, type of employment, number of children, age, work shift, and work experience), Sibriashring emotional intelligence questionnaire (including self-awareness, self-control, social awareness, social skills, and self-motivation), and Spector job satisfaction survey (nine dimensions of pay, promotion, supervision, benefits, contingent rewards, operating procedures, co-workers, nature of work and communication). In addition, data analysis was performed in SPSS version 16 using Pearson's correlation coefficient, independent t-test, and one-way analysis of variance.

Results: About $62 \%$ of the participants were female and the rest $(38 \%)$ were male. In terms of marital status, $34 \%$ of the subjects were single and $66 \%$ were married. In addition, the majority of the participants were below 30 years and had a BSc. According to the results, there was no significant relationship between emotional intelligence and occupational satisfaction $(\mathrm{P}>0.05)$. On the other hand, a significant correlation was observed between the social skills of emotional intelligence and dimensions of promotion, supervision, and communication. In this regard, the relationship with promotion and supervision was reverse, while it was direct with communication. In addition, a significant correlation was observed between the social awareness dimension of emotional intelligence with the subscales of contingent rewards and communication, which was direct regarding the latter but poor and reverse in terms of the former. Moreover, we detected a poor, direct, and significant association between the self-awareness dimension of emotional intelligence and the total score of occupational satisfaction. Furthermore, there was a significant correlation between self-motivation and total occupational satisfaction and the dimensions of contingent rewards and communications. In this regard, the relationship was poor and direct with total occupational satisfaction and contingent rewards. In addition, we found a poor, reverse, and significant relationship between the self-control dimension of emotional intelligence and dimensions of benefits, co-workers, and communication. Moreover, the total emotional intelligence had a significant correlation with the dimensions of promotion, benefits, and communication, which was poor and

\footnotetext{
1. Lecturer, Department of Operating Room, faculty of Nursing and Midwifery, Kurdistan University of Medical Sciences, Sanandaj, Iran

2. MS in Midwifery, Imam Khomeini Divandareh Hospital, Kurdistan University of Medical Sciences, Sanandaj, Iran 3. Student Research Committee, Kurdistan University of Medical Sciences, Sanandaj, Iran (Corresponding author) Tel: +989180819368_ Email: foroughiasra@gmail.com

4. Lecturer, Environmental Health Research Center, Kurdistan University of Medical Sciences, Sanandaj, Iran
} 
reverse with communication, reverse with benefits, and direct with communication. The mean emotional intelligence was 112, which demonstrated the favorable level of emotional intelligence of the participants. Moreover, the mean occupational satisfaction was 121.5, which was below moderate.

Conclusion: According to the results of the study, the occupational satisfaction of operating room technicians was significantly lower than moderate. Overall, occupational satisfaction is affected by various factors, which change depending on time, location, and social situations. It seems that social, economic, and cultural situations of a society significantly determine the factors affecting occupational satisfaction. The occupational satisfaction of operating room technicians affects their work quality. Therefore, officials should pay more attention to this issue by holding educational workshops and courses to increase the occupational satisfaction of operating room technicians. Given the high workload of these individuals, researchers had limited time for filling the questionnaires, which was resolved by referring to the participants in evening and night shifts and on holidays when they had a lower workload. The researchers referred to the operating room to fill the questionnaire. Given the rapid growth of technology and advances in the field of health sciences, it is necessary to conduct a similar study with more up-to-date tools. The results of the present study can be presented to the officials of the University Educational and Medical Center in order to find a solution or design interventions to increase the welfare facilities in the workplace and provide appropriate promotions and favorable working environment conditions to improve the job satisfaction of operating room technicians.

Keywords: Emotional Intelligence, Occupational Satisfaction, Operating Room

\section{Conflict of Interest: No}

How to Cite: Rezagholi P, Foroughi P, Foroughi A, Shahsawari S. The Association of Emotional Intelligence and Job Satisfaction in Operating Room Technologists. Iran Journal of Nursing. 2019; 32(121):82-93.

Received: 21 Sep 2019

Accepted: 21 Dec 2019 


\title{
ارتباط هوش هيجانى با رضايت شغلى در تكنولوزيستهاى اتاق عمل
}

\author{
يبيمان رضاقلى '، يريا فروغى '، اسراء فروغى"، سيروس شهسوارىع
}

\begin{abstract}
جكيده
زمينه و هدف: رضايت شغلى ازعوامل مهم و تأثيركذار بر افزايش ميزان بهره ورى سازمانها مى باشد و هوش هيجانى مجموعه مهارتهائى است كه

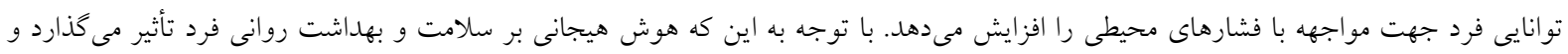

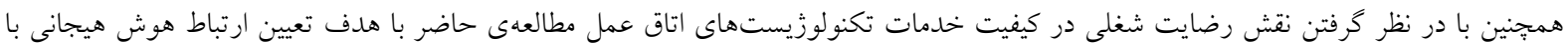
رضايت شغلى در تكنولوزيستهاى اتاق عمل انجام شد.
\end{abstract}

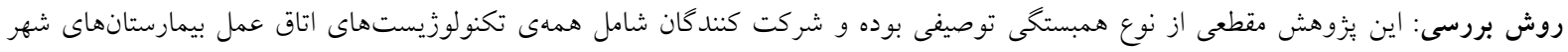

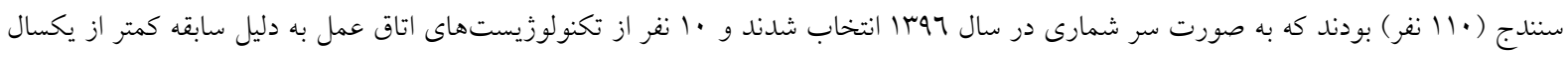

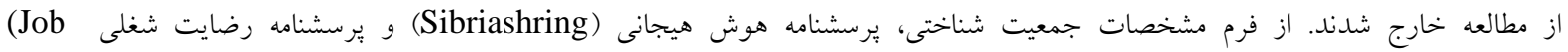
SPSS نسخه 17 و ضريب همبستخى بيرسون ، Satisfaction Spector) و آناليز واريانس يك طرفه تجزيه و تحليل كرديد.

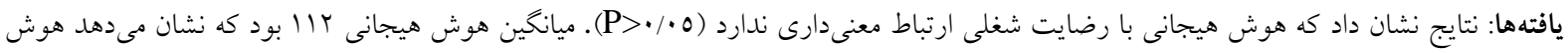

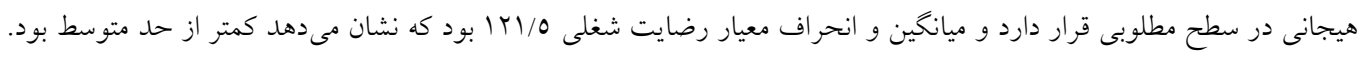

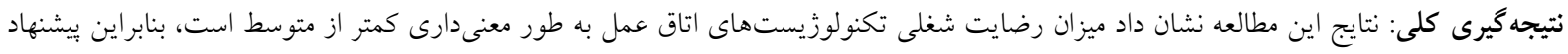

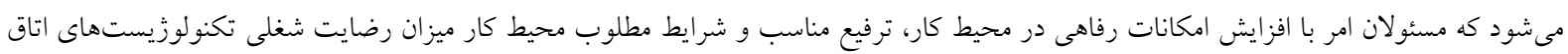
عمل را در سطح مطلوبى قرار دهند.

كليد وازهها: هوش هيجانى، رضايت شغلى، اتاق عمل

تعارض منافع: ندارد

تاريخ دريافت: · ·

تاريخ هذيرش: ·

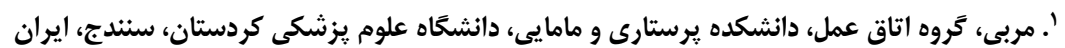

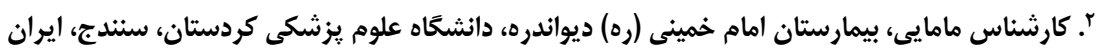

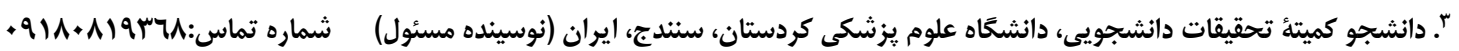
Email: foroughiasra@gmail.com ؟.. مربى ،مر كز تحقيقات بهداشت محيط، دانشكاه علوم يزشكى كردستان، سندج، ايران 
رضايت شغلى مجموعه احساساتى است كه هر فرد

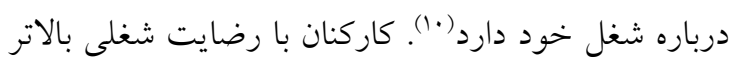

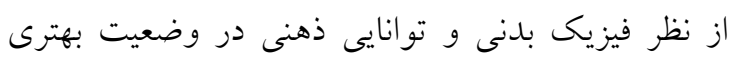

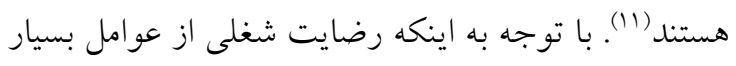

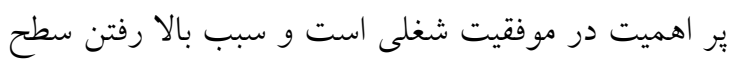

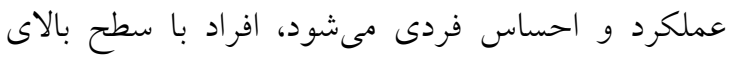
رضايت شغلى داراى انخيزه بيشترى در انجام وظيفه

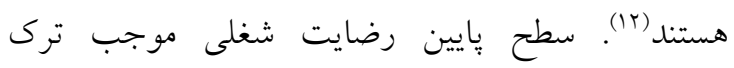
خدمت و يا منجر به تعويض شغل خواهد شد به به طورى رئن كه طبق گزارش انجمن استخدام آمريكا، ميزان تغيير شغل

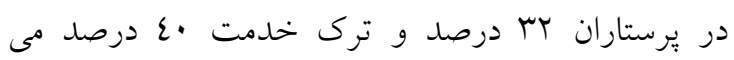

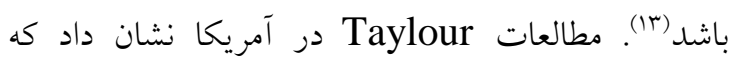
رضايت شغلى در يرستاران با ارتقاء كيفيت خدمات ارائه

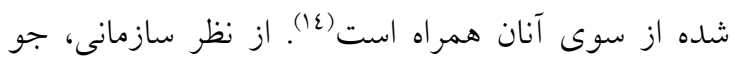

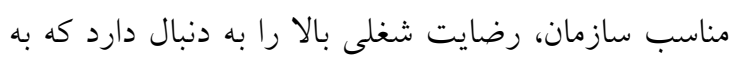

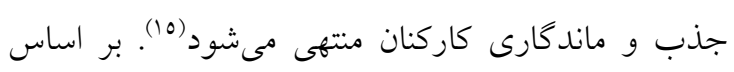

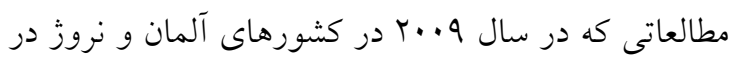

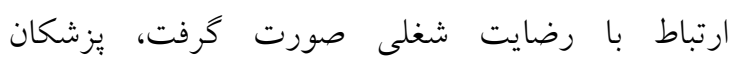

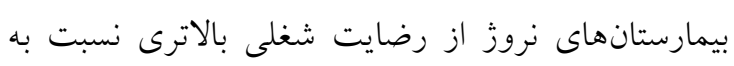

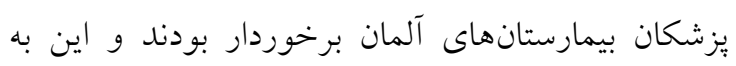

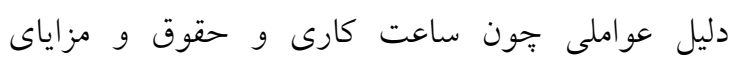
مناسب در بيمارستانهاى نروز بود(17). نتايج مطالعات

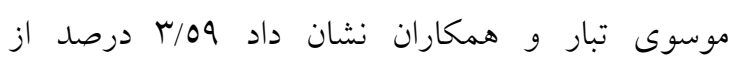

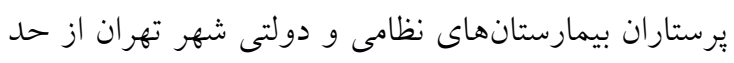

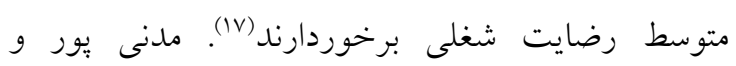

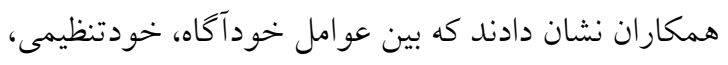

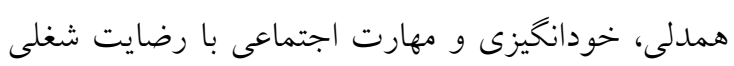

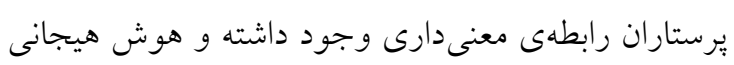
بر روى رضايت شغلى اين يرستاران تأثير مثبت دارد(^).

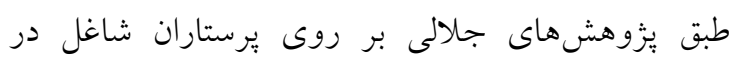

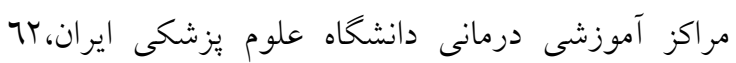

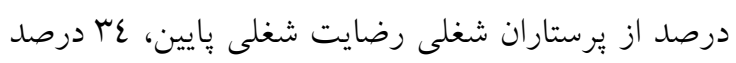

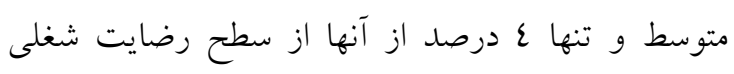

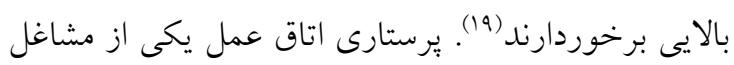

\section{مقدمه}

Mayer و Salovey

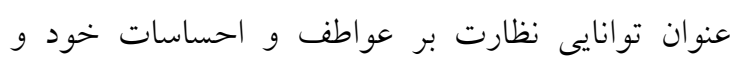

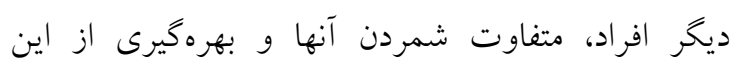
اطلاعات براى هدايت تفكر و عمل فرد تعريف كرده

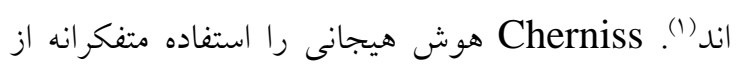
احساسات تعريف كرده كه به فرد كمك مى كند با بهره كيرى از آن، تفاوت بين عواطف و احساسات را كترل

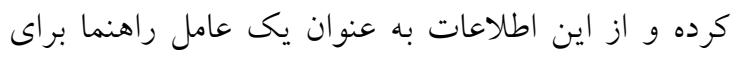

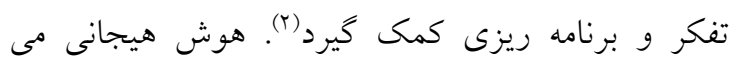

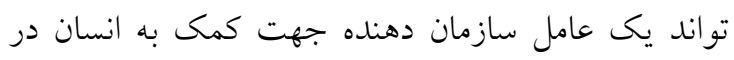
شرايط آسيب زا باشد (r). در كذشته عوام معتقد بودند كه دهان

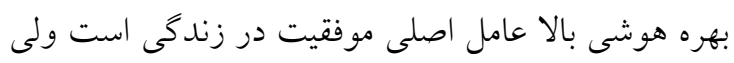

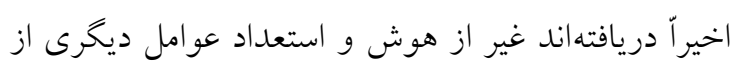
جمله هوش هيجانى در موفقيتها دخيل هستند (ع). افراد

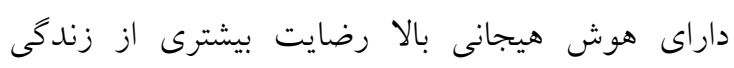

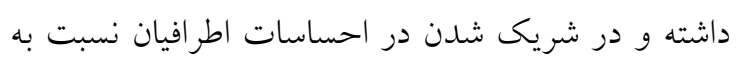
ديخران متفاوت بوده و افرادى منظم، خوش بين، خون كرم و با انكيزه هستند (ع). هوش هيجانى در موفقيت افراد

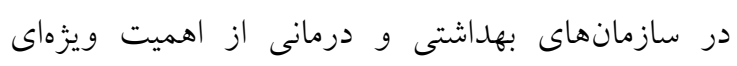

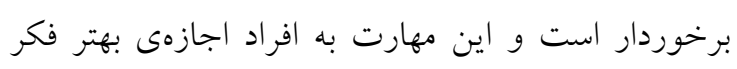

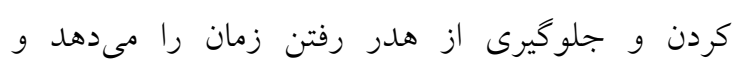

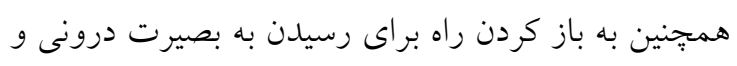

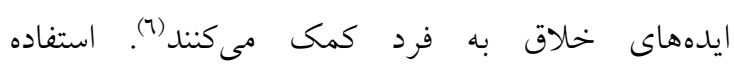

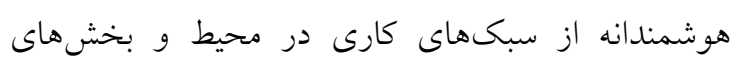
مختلف بستخى به هوش هيجانى دارد و عاملى تأثير كذار

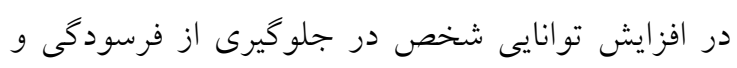

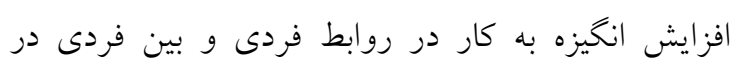

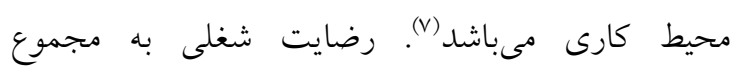

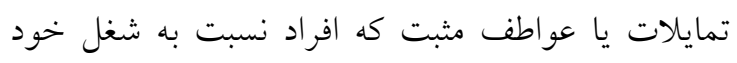
دارند، كفته مىشود كه حقوق، ارتباطات، رويهها، نظم كار و ويزگكىهاى شخصيتى كاركنان مىتواند روى آن تأثير

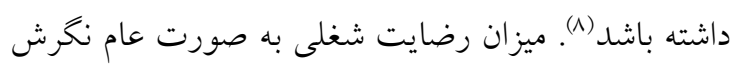

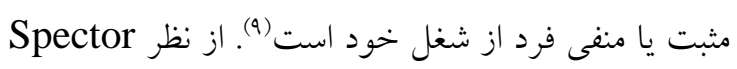


بود. ضمن رعايت اصول اخلاقى مصوبه كميته اخلاق

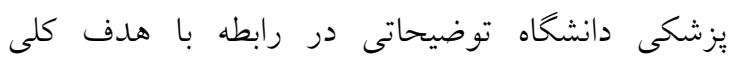

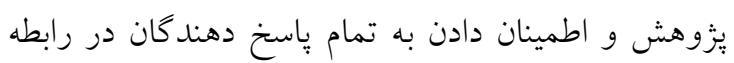

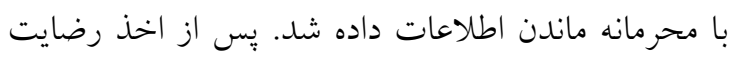
كتبى آكاهانه از واحدهاى يُزوهش جماندع آندان آورى داده انجام

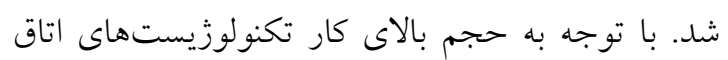

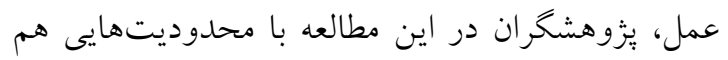

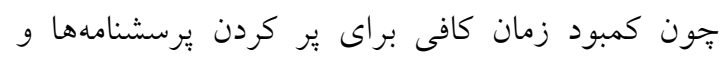

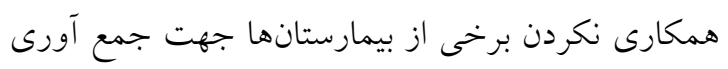

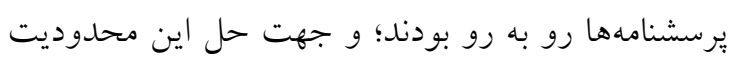
ها در نوبتهاى عصر و شب و يا روزهاى تعطيل كه بار

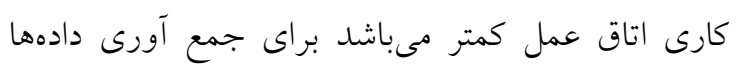
مر اجعه شد. براى جمع آورى دادهها ازفرم مشخصات جمعيت شناختى (شامل جنسيت، وضعيت تأهل، تحصيلات، ميزان درآمد، نوع استخدام، تعداد فرزند، سن، ساعت كار

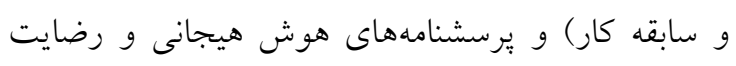

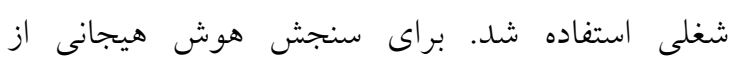

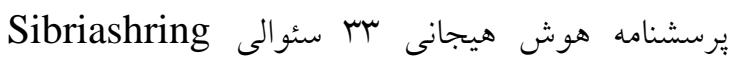

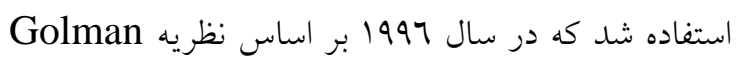
توسط Sibriashring تدوين شده است. كويههاى اين برسشنامه به شيوه ليكرت به صورت هميشه (الف)، اغلب

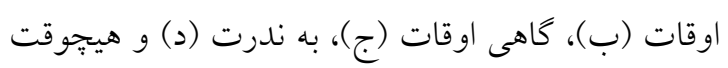

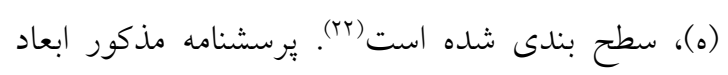

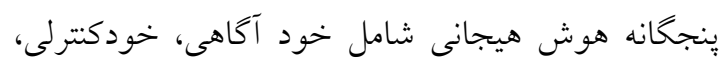

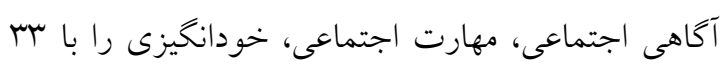

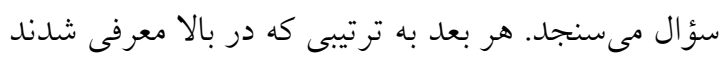

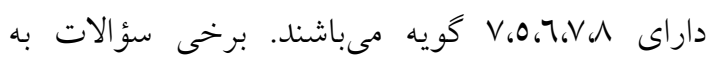

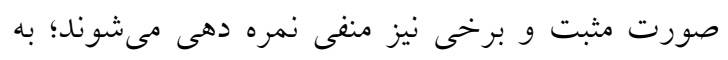

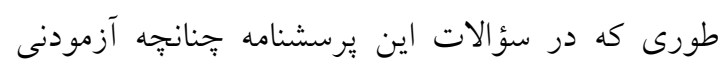

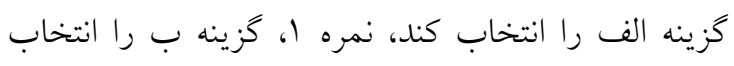

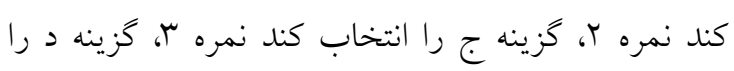

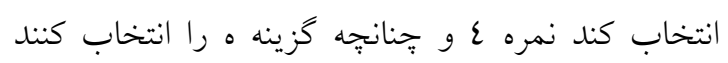

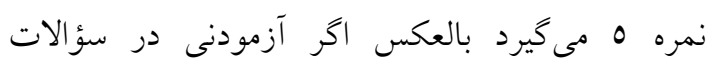

مهم در محيطهاى بهداشتى درمانى بوده كه ارائه خدمات

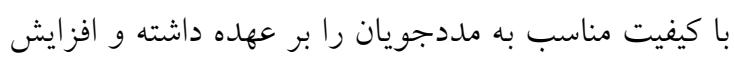
رضايت شغلى اين دسته از يرستاران ارتقاء كيفيت

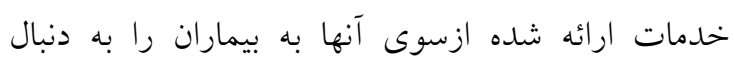
دارد (r)( Gardner و Stok در مطالعهاى در كشور

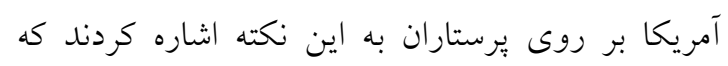

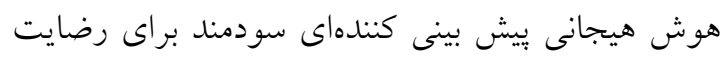

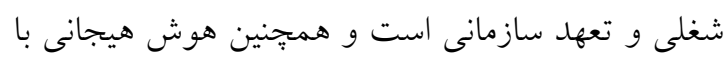

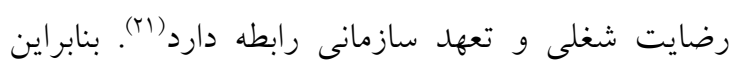
ضرورى است عوامل مرتبط با رضايت شغلى اين گروها از كاركنان نظام سلامت مورد كنكاش و بررسى قرار كيرد.

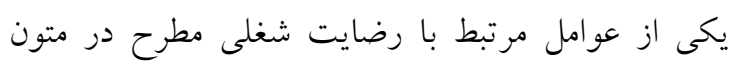

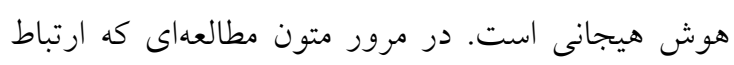

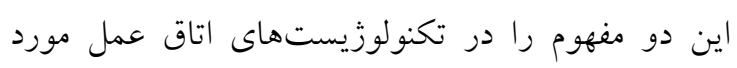

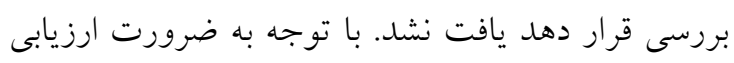

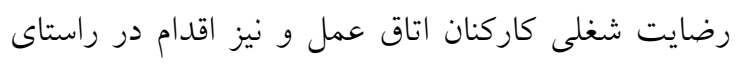

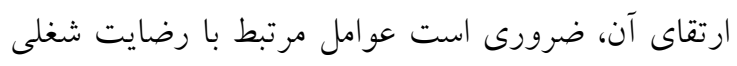

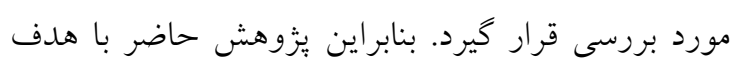

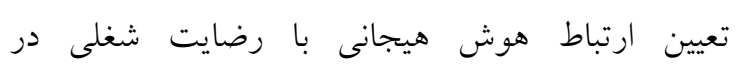
تكنولوزيست هاى اتاق عمل انجام شد.

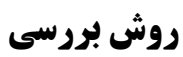

اين مطالعه مقطعى به روش همبستكى توصيفى بر روى

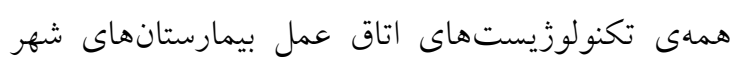

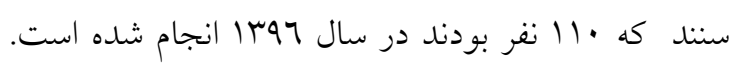
اين يُزوهش با كد اخلاق در معاونت بزوهشى دانشخاه علوم بزشكى كردستان تأييد

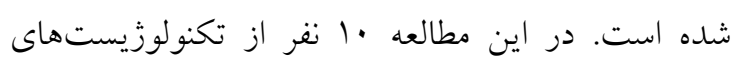
اتاق عمل به دليل سابقه كمتر از يكسال وارد مطالعه نشدند. معيار ورود به مطالعه شامل: ا. حداقل يكسال كار

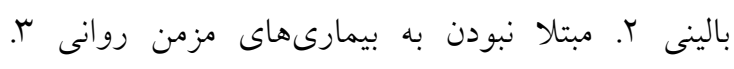

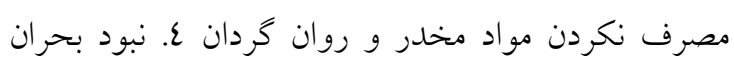

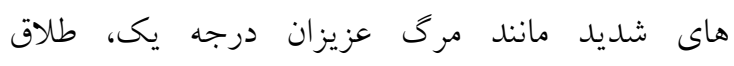
ورشكستخى و از دست دادن اموال در شش ماه كذشته 
Spector

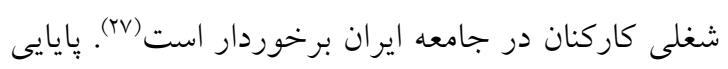

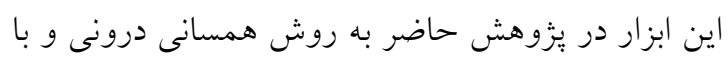

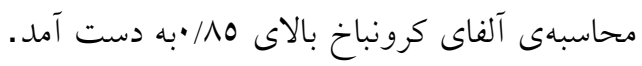

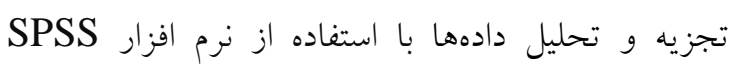

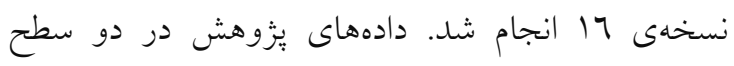

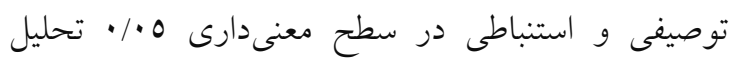

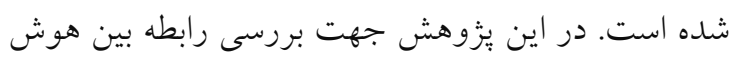
هيجانى و رضايت شغلى از ضريب همبستكى بييرسون

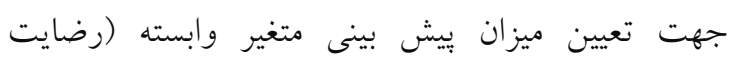
شغلى) توسط متغير مستقل (هوش هيجانى) استفاده شد. جهت بررسى نقش متغيرهاى جمعيت شناختى (شامل

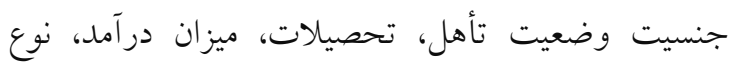
استخدام، تعداد فرزند، سن، ساعت كار و سابقه كار) از از

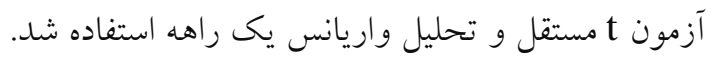

\section{يافتهها}

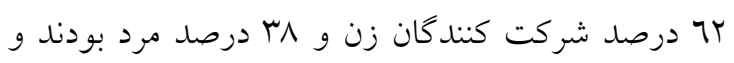

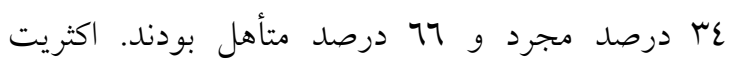

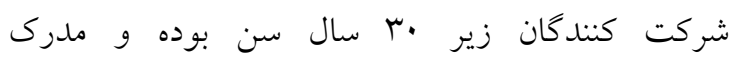
كارشناسى داشتند (جدول شماره ()). در بررسى ها ارتباط

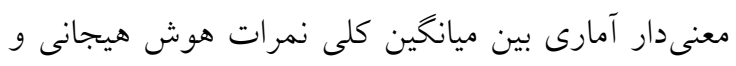

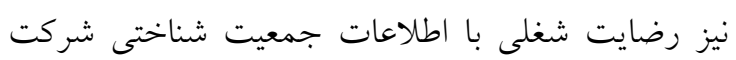

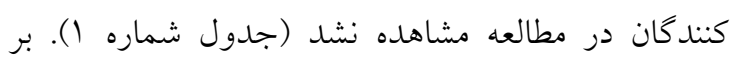

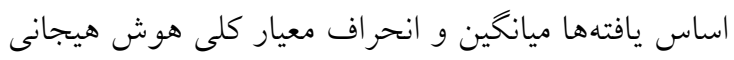

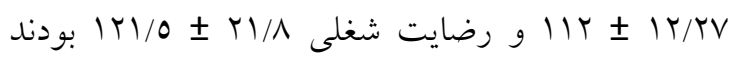

$$
\text { (جدول شماره (Y). (ج) }
$$

(1)

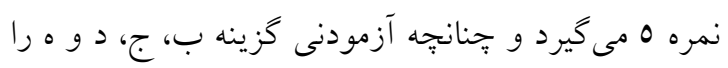
انتخاب كند، به ترتيب نمره كمترى مى كيرد. هوش

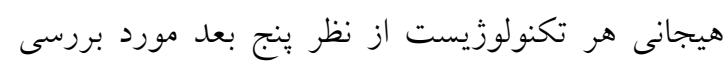

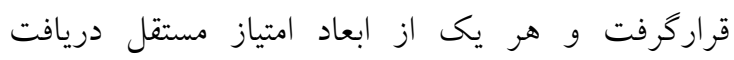

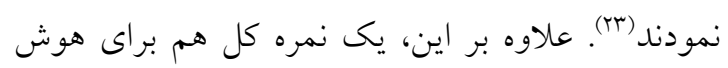
هيجانى تكنولوزيست اختصاص يافت. دامنه نمرات

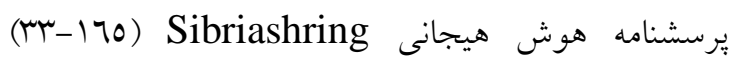

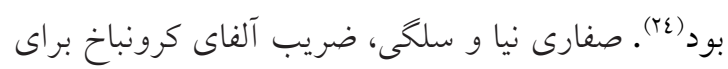

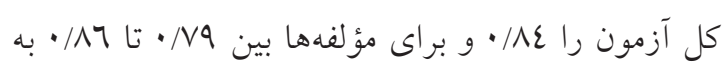

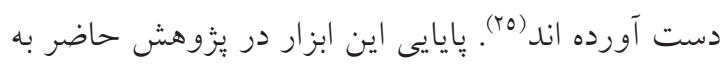

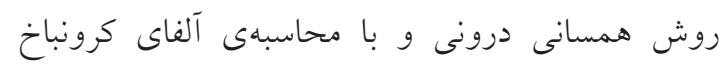

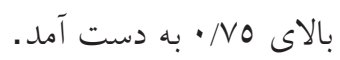
براى سنجش رضايت شغلى از يرسشنامه رضايت شغلى دوسلى (Job satisfaction spector1985) JSS شد. اين برسشنامه، رضايت شغلى را در نه آنه حيطة

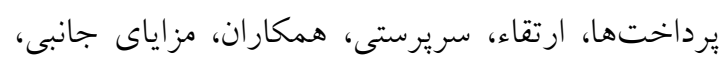

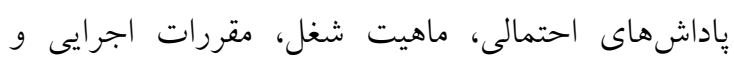

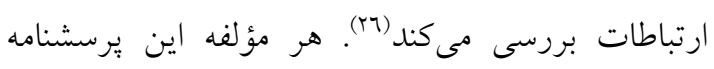

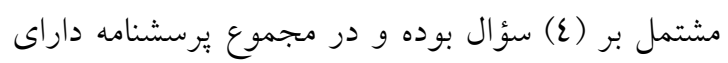

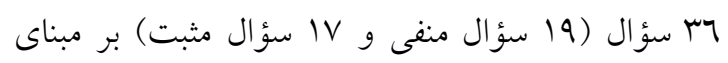
مقياس شش كزينهاى ليكرت است. در سؤالهاى مثبت، طيف نمره از يك (كاملاً مخالفم) تا شش (كاملاً موافقم)

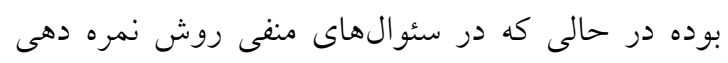

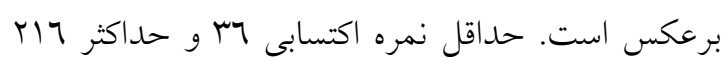

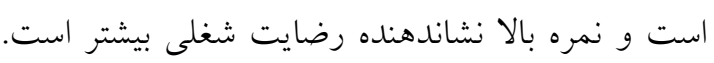

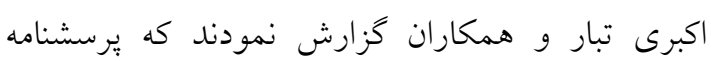


جدول شماره ا: توزيع فراوانى واحدهاى مورد يزوهش برحسب متغيرهاى جمعيت شناختى و ارتباط آن ها با هوش هيجانى و رضايت شغلى

\begin{tabular}{|c|c|c|c|c|c|c|c|}
\hline \multicolumn{2}{|c|}{ رضايت شغلى } & \multicolumn{2}{|c|}{ هوش هيجانى } & \multirow[t]{2}{*}{ درصد } & \multirow[t]{2}{*}{ ت تعداد } & \multirow{2}{*}{\multicolumn{2}{|c|}{ متغير }} \\
\hline نتيجه آزمون & انحراف معيار \ميانگين & نتيجه آزمون & انحراف معيار 土 ميانخين & & & & \\
\hline $\mathrm{p}=\cdot / / q 1$ & $|r \cdot / \Lambda 7 \pm r| / / r$ & $\mathrm{p}=\cdot / 01$ & & $7 r$ & $7 r$ & زن زن & جنسيت \\
\hline $\begin{array}{c}\mathrm{T}=\cdot / \wedge \mathrm{T} / \\
\mathrm{df}=q \wedge\end{array}$ & IYK/ITE IV/YT & $\begin{array}{c}\mathrm{T}=\cdot / 771 \\
\mathrm{df}=9 \wedge\end{array}$ & $\| 11 / \wedge 1 \pm q / r q$ & $\mu_{\Lambda}$ & щ & 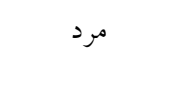 & \\
\hline $\mathrm{p}=\cdot / \pi \mu \varepsilon$ & $11 V \pi \kappa \pm 1 \% / \mu 7$ & $\mathrm{p}=\cdot / \wedge 79$ & ||$r / 0 \varepsilon \pm|r / r|$ & $r \varepsilon$ & $r \varepsilon$ & مجرد & وضعيت \\
\hline $\begin{array}{l}T=119 \\
d f=91\end{array}$ & $11 \% / \pi 7 \pm 1 / / 17$ & $\begin{array}{c}\mathrm{T}=\cdot / 179 \\
\mathrm{df}=91\end{array}$ & $11 K / r 7 \pm 1 r / 20$ & 77 & 77 & 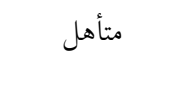 & تأهل \\
\hline $\mathrm{p}=\cdot / \mu \wedge \vee$ & $1 Y \varepsilon / \pi O \pm 19 / \% 7$ & $\mathrm{p}=\cdot / / 79$ & $\| 11 / 1 r \pm 1 \cdot / r 1$ & $r$. & $r$. & كاردان & تحصيلات \\
\hline $\begin{array}{c}\mathrm{T}=\cdot / \wedge 79 \\
\mathrm{df}=9 \wedge\end{array}$ & $|r \cdot| \Sigma| \pm r \cdot| \Sigma \mid$ & $\begin{array}{c}\mathrm{T}=\cdot / q \cdot r \\
\mathrm{df}=q \wedge\end{array}$ & $\| r / r r \pm I r / r O$ & v. & $v \cdot$ & كارشناس & \\
\hline $\mathrm{p}=\cdot / 7 r \varepsilon$ & $11 r / r 7 \pm$ rI/Vo & $\mathrm{p}=\cdot / r \wedge r$ & $11 \varepsilon / V O \pm 1 \varepsilon / r T$ & ro & To & $1 / 0-r$ & ميزان در آمد، \\
\hline $\mathrm{F}=\cdot / \varepsilon \vee \varepsilon$ & $119 / r 7 \pm r \mid / 11$ & $F=\cdot / 9 V r$ & $11 / r \varepsilon \pm 11 / r$. & or & or & $r / 0-T$ & ميليون تومان \\
\hline $\mathrm{df}=9 \wedge$ & $|r| / \Lambda 7 \pm 12 / 00$ & $\mathrm{df}=9 \wedge$ & $110 / 00 \pm 11 / 10$ & rr & rt & $r / 0-r$ & \\
\hline $\mathrm{p}=\cdot / \wedge \vee \wedge$ & $|r| \pi \cdot \pm \mid r / r 7$ & $\mathrm{p}=\cdot / \mathrm{or} \varepsilon$ & $\| \varepsilon / 1 \wedge \pm 1 r / 10$ & rT & MT & ييمانى & \\
\hline$F=\cdot /|\mu|$ & $|r \cdot \pi| \pm 1 N / 19$ & $\mathrm{~F}=. / 701$ & $11 r / 10 \pm 11 / \pi 0$ & $\{7$ & $\varepsilon\rceil$ & رسمى & نوع استخدام \\
\hline $\mathrm{df}=99$ & $\mid r r / \varepsilon \wedge \pm I V / r T$ & $\mathrm{df}=99$ & $111 / 70 \pm 1 r / 00$ & rr & Tr & قراردادى & \\
\hline$p=\cdot / 9 \cdot 0$ & $\mid r \varepsilon / 1 Y \pm 9 / r 7$ & $\mathrm{p}=\cdot / \mathrm{r} \circ \mathrm{V}$ & $\|r / 20 \pm \mid r /\|$ & ov & ov & بدون فرزند & \\
\hline $\mathrm{F}=\cdot / \mathrm{V} 10$ & $\mid r \varepsilon / \varepsilon r \pm q / 1 r$ & $F=1 / 1 T$ & $117 \varepsilon r \pm 11 / r_{0}$ & ro & To & ا فرزند & تعدادفرزند \\
\hline $\mathrm{df}=99$ & $1 \pi / r q \pm 17 / 1 r$ & $\mathrm{df}=99$ & $11 \cdot / r 7 \pm 11 / 21$ & 11 & 11 & r فرزند و بالاتر & \\
\hline $\mathrm{p}=\cdot / \mathrm{V}$ & $1 r \cdot / T 0 \pm 9 / 7 \varepsilon$ & $\mathrm{p}=\cdot / \mu 71$ & $111 / 70 \pm 9 / 10$ & $\varepsilon$ & そ1 & زير ·r & \\
\hline$F=100$ & $\mid r M / 1 T \pm 1 \cdot / 10$ & $F=11 \mu / 1$ & $\|\varepsilon / 1 \wedge \pm\| / \gamma \wedge$ & $r \varepsilon$ & $r \varepsilon$ & $r q-r$. & سن، سال \\
\hline $\mathrm{df}=99$ & $|1 r / \varepsilon \cdot \pm 1 \cdot / \varepsilon|$ & $\mathrm{df}=99$ & $111 / r 7 \pm 1 \cdot / \mu \varepsilon$ & ro & ro & •ع به بالا & \\
\hline$p=\cdot / 019$ & Iro/rר $\pm 1 \varepsilon / T Y$ & $\mathrm{p}=\cdot / / \vee \varepsilon$ & $110 / \mu r \pm 1 \varepsilon / 1 \varepsilon$ & rA & rA & •ما به پايين & \\
\hline $\mathrm{F}=r / / 7$ & IrT/K & $\mathrm{F}=\cdot / 019$ & $111 / 20 \pm 1 \cdot / 1 r$ & $\varepsilon$ & そ1 & $|r| 9-11 \mid$ & ساعت كار \\
\hline $\mathrm{df}=99$ & $|r \varepsilon / v| \pm v / 10$ & $\mathrm{df}=99$ & $\|r / v \varepsilon \pm\| / r$. & m & m & . r ب به بالا. & \\
\hline $\mathrm{p}=\cdot /|r|$ & Iro/Or $\pm 9 / T_{0}$ & $\mathrm{p}=\cdot 100 \mathrm{~V}$ & $\|r / \varepsilon 7 \pm\| r / 1 T$ & $7 T$ & $7 \pi$ & زير ·1 & سابقه كار، \\
\hline$F=1 / 79$ & $\mid r q / 7 \varepsilon \pm 1 \varepsilon / 1 \Lambda$ & $F=1 / r \varepsilon$ & $\| \varepsilon / \Lambda 7 \pm 1 \cdot / \mu_{0}$ & rI & rl & $19-1$ & سال \\
\hline $\mathrm{df}=99$ & 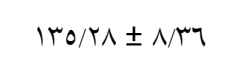 & $\mathrm{df}=99$ & $\mid 1 \cdot / \mu 1 \pm 1 \cdot / r$. & IV & IV & •r به بالا & \\
\hline
\end{tabular}

جدول شماره r: ميانغَين و انحراف معيار هوش هيجانى و رضايت شغلى در افراد مورد يزوهش مين

\begin{tabular}{|c|c|c|}
\hline ميانخين و انحراف معيار & تعداد & متغير وابسته \\
\hline$\|r \pm\| r / T V$ & $1 \cdots$ & هوش هيجانى \\
\hline$|r| / 0 \pm r \mid / \Lambda$ & $1 \cdots$ & رضايت شغلى \\
\hline
\end{tabular}

ميزان هوش هيجانى تكنولوزيستهاى اتاق عمل بيمارستانهاى شهر سنتد از ميانه نمره ابزار بالاتر است.

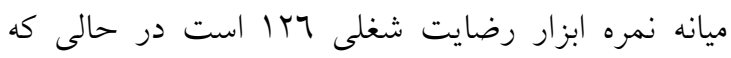

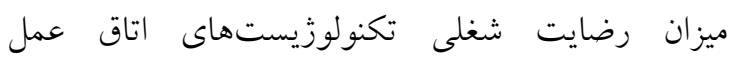

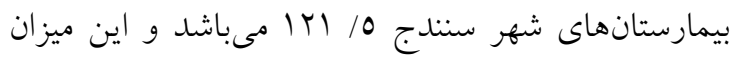

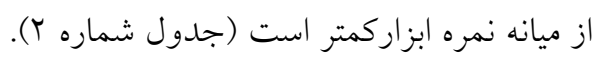


مستقيم داشت. بين خود انخيزگى با رضايت شغلى كل و

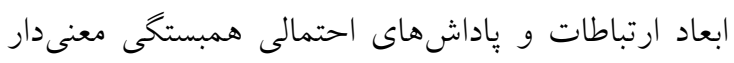

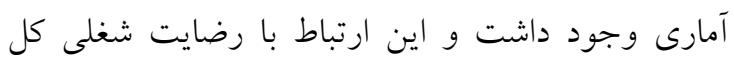

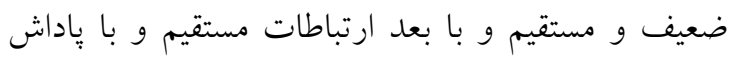

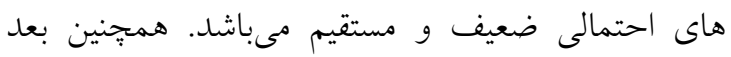
خودكنترلى هوش هيجانى با ابعاد مز اياى جانبى، همكاران

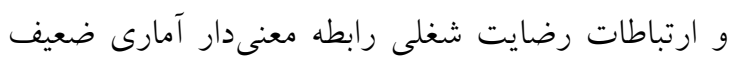
و معكوس داشت. هوش هيجانى كل با ابعاد ارتقاء،

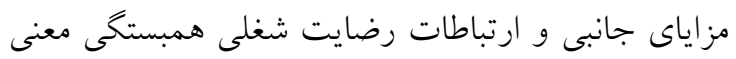

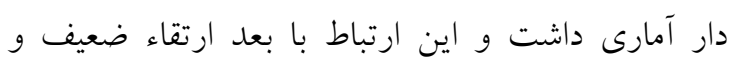
معكوس، با بعد مزاياى جانبى معكوس و با بعد ارتباطات

$$
\text { مستقيم مىباشد(جدول شماره ؟). }
$$

براساس نتايج رابطه معنىدار آمارى بين نمره كل هوش

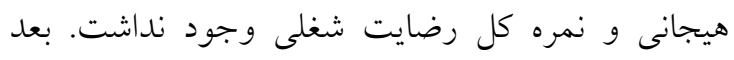

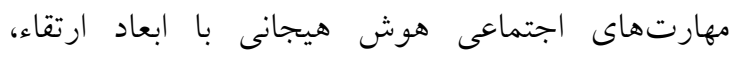

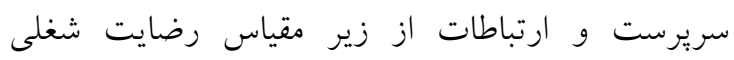

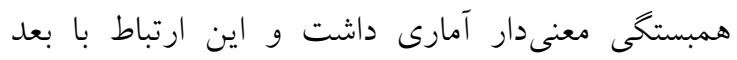
ارتقاء و سريرست ضعيف و معكوس و با بعد ارتباطات

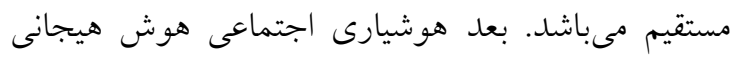

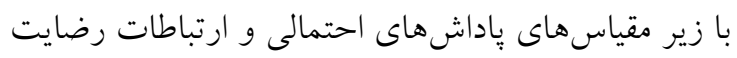

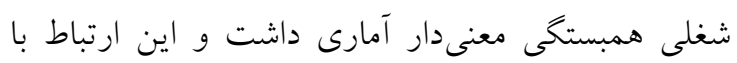

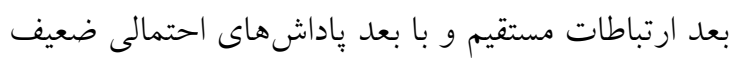

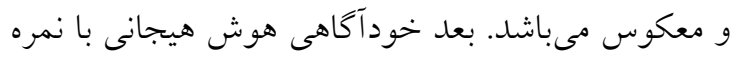

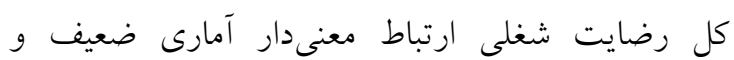

جدول شماره ب: ارتباط بين ميانكَين نمره كل هوش هيجانى و زير مقياسهاى آن با ميانكَين نمره كل رضايت شغلى و زير مقياسهاى آن

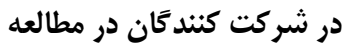

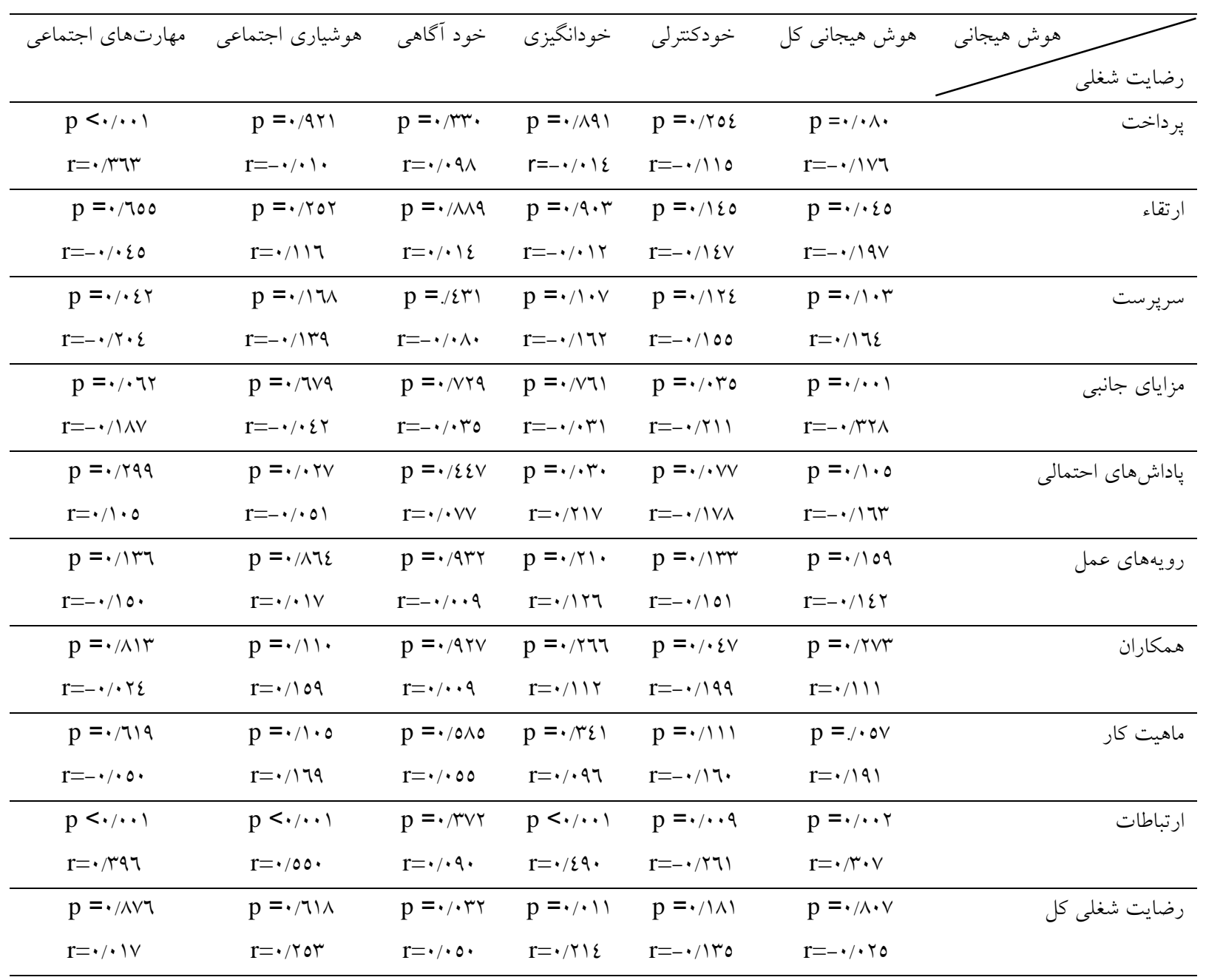


كاهش اين رضايت شغلى مؤثر است نوبت كارى مى

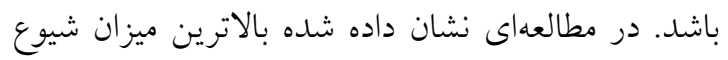
مربوط به مشكلات روحى- روانى، كوارشى و اثرات

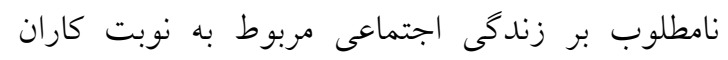

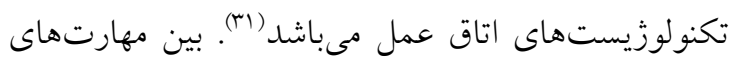

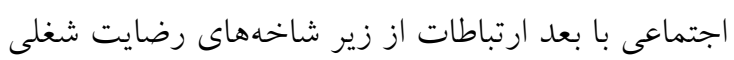

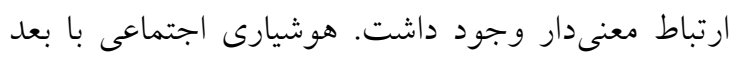

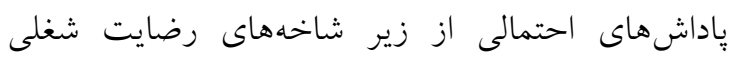

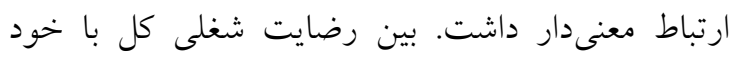

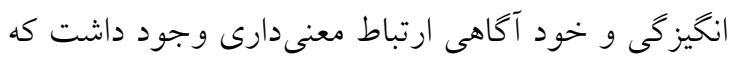

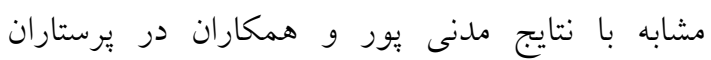

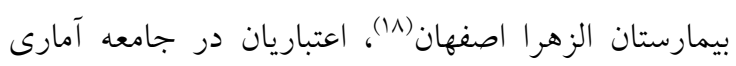

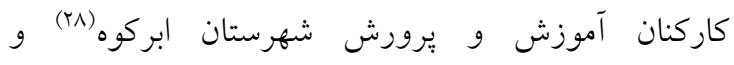
Utriainen فرد موجب خوش بينى و ابتكار عمل مىشود و فرد براى

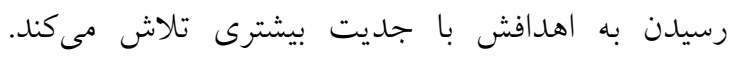

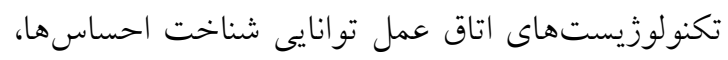
نقاط ضعف و قوت خويش و عوامل به وجود آورنده

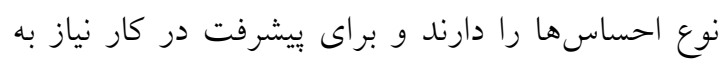

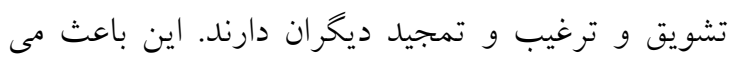
شود كه خود را قوى، توانمند و سرشار از انرزى بدانند.

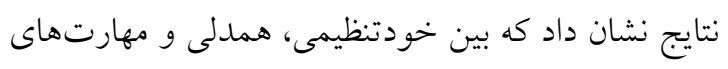
اجتماعى با رضايت شغلى تكنولوزيستهاى اتاق عمل

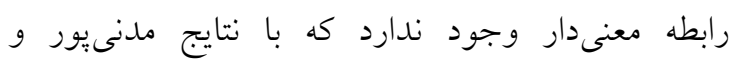

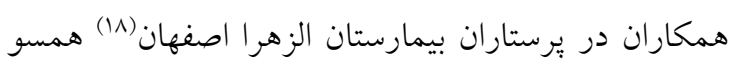

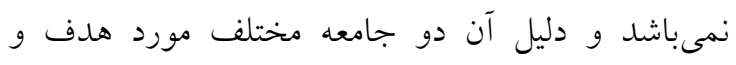

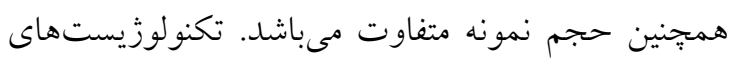
اتاق عمل از بروز اختلالات هيجان و تكانشهاى مونه موجود

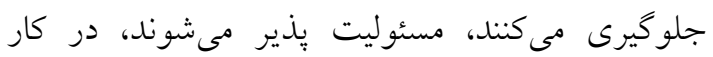

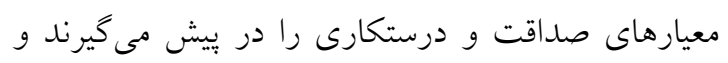

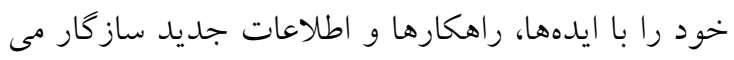

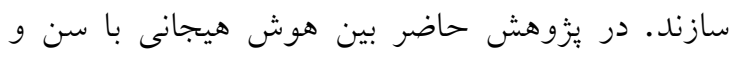

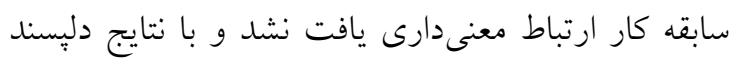

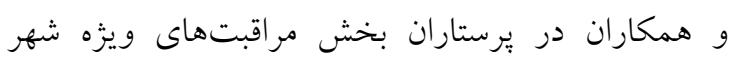

\section{بحث و نتيجه كيرى}

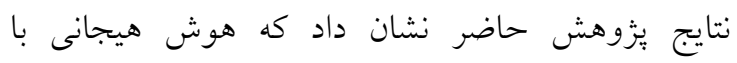

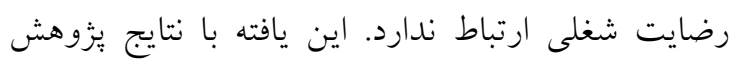

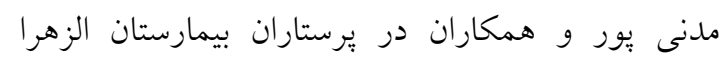

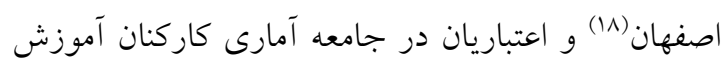

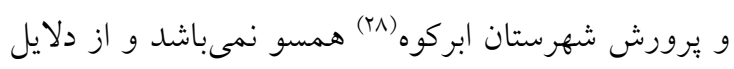

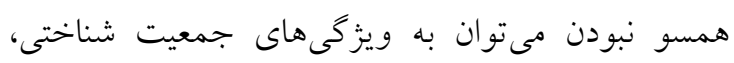

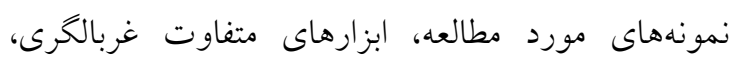
تفاوتهاى فرهنكى و رفتارى جوامع اشاره كرد. نتايج

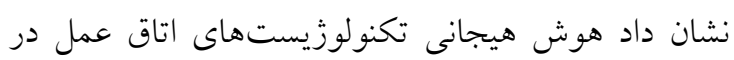

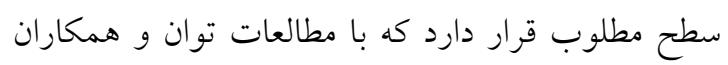

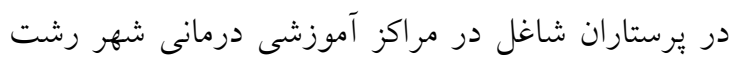

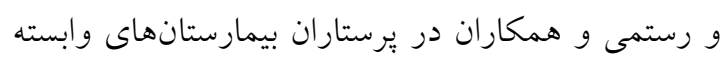

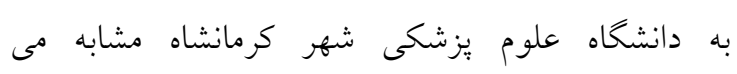

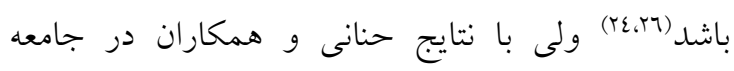
تكنولوزيستهاى جراحى در تهران (Y9) كه به اين نتيجه

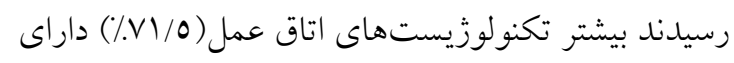
هوش هيجانى متوسط بودند همسو نمىباشد. شايد اين

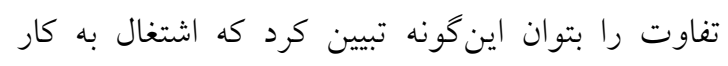

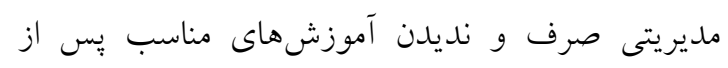
استخدام در سازمان، منجر به ضعف به كارگيرى صحيح

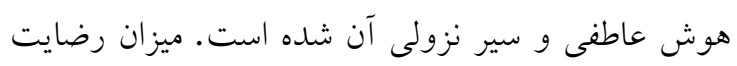

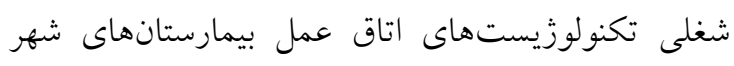

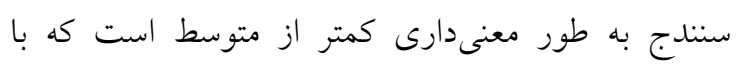

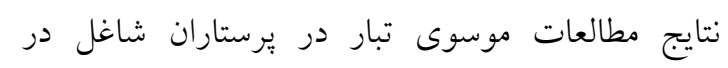

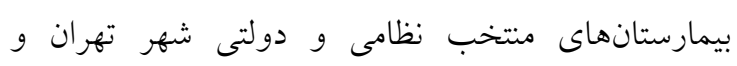

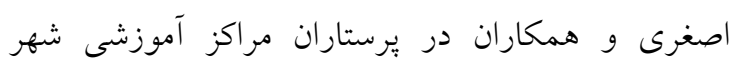

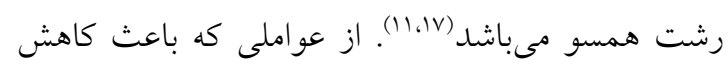

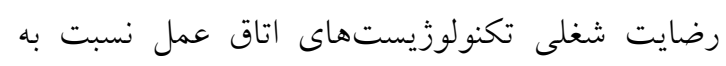

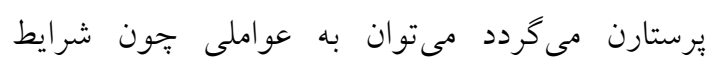

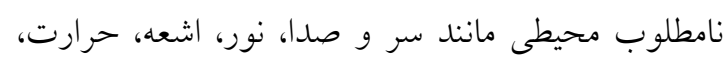

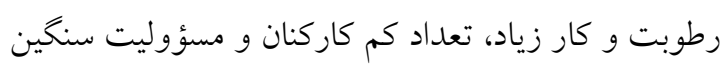
و همجنين كمى حقوق و مزايا نسبت به نوع فعاليت

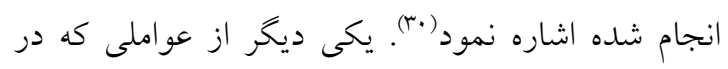


بر رضايت شغلى است. رضايت شغلى تكنولوزيستهاى

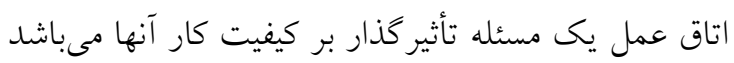

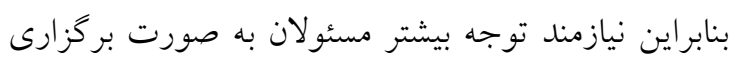

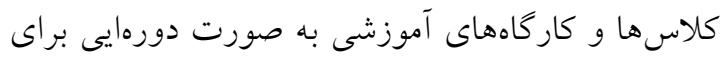

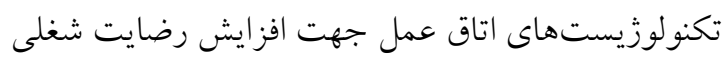

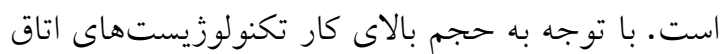

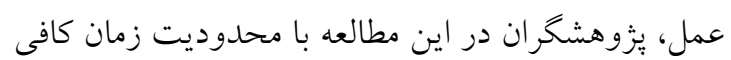

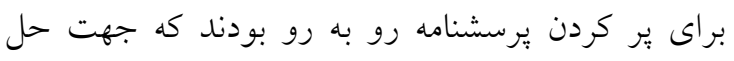

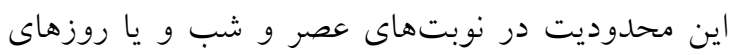
تعطيل كه بار كارى اتاق عمل كمتر است جهت بر كردن

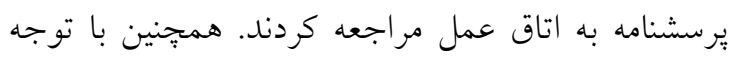

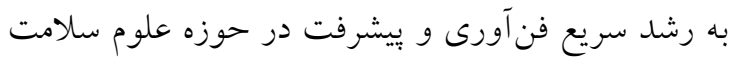

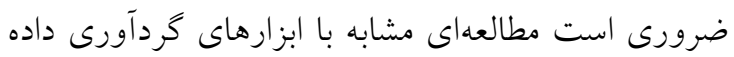

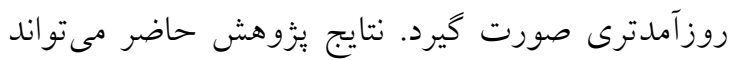

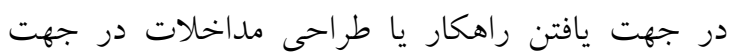

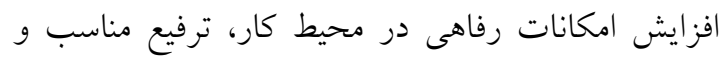

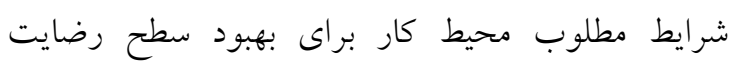
شغلى تكنولوزيستهاى اتاق عمل، به مسئولين مركز آموزشى و درمانى دانشخاه ارائه شود.

تعارض منافع: هيج كونه تضاد منافع از سوى نويسند كان كزارش نشده است.

\section{تقدير و تشكر}

اين يزوهش با حمايت مالى معاونت تحقيقات و فن آورى دانشخاه علوم بزشكى كردستان انجام شده است. بدينوسيله نويسندكان اين مقاله بر خود لازم مىدانند كه

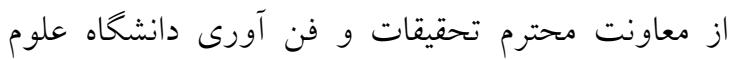
يزشكى كردستان، رياست، مديران و تكنولوزيستهاى نهاى اتاق عمل بيمارستانهاى سنتدج كه بدون همكارى آنها انجام اين مطالعه ميسر نبود تشكر و قدردانى كنند.
تهران، Landa و همكاران در برستاران كشور اسبانيا، كه رابطهاى بين هوش هيجانى و سن يافت نكردند، همسو

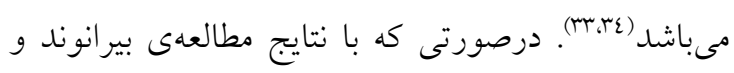

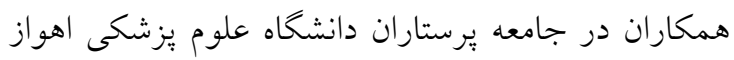

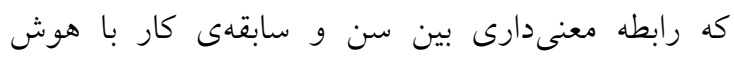
هيجانى و يزّوهش قادرى و شمسى كه همبستخى مستقيم بين سن با هوش هيجانى را نشان دادند، مغايرت

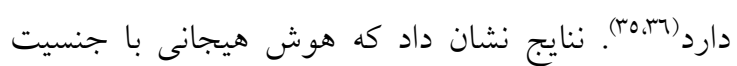
ارتباط معنىدارى نداشت كه با نتايج رستمى و همكاران

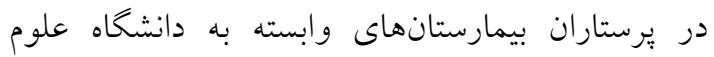

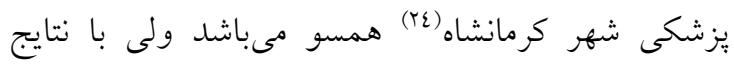

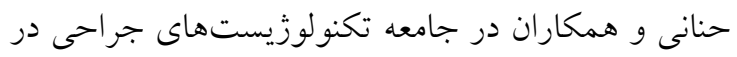

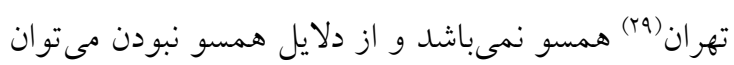

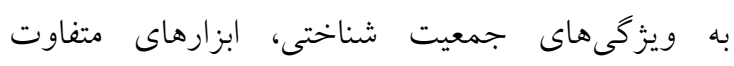
غربالكرى رضايت شغلى، تفاوتهاى فرهنكى نسبت دادئ داد. در اين مطالعه بين هوش هيجانى با وضعيت تأهل رابطه

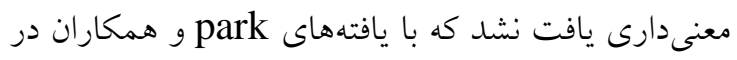

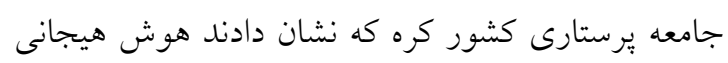

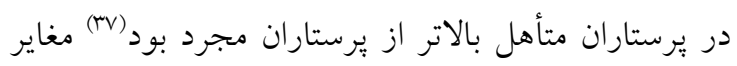

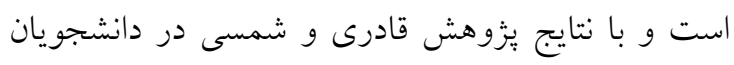

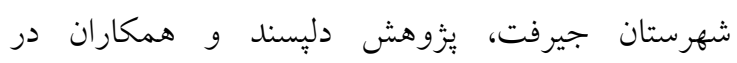

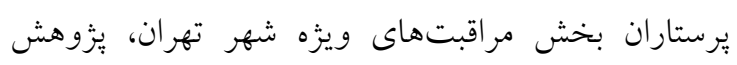

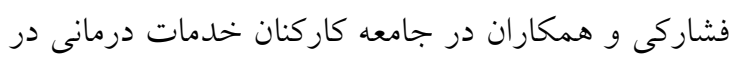
تهران، يزوه هش حنانى و همكاران در جامعه تكنولوزيست دهان

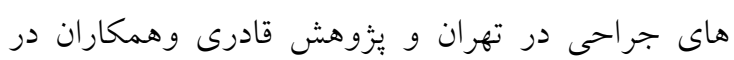

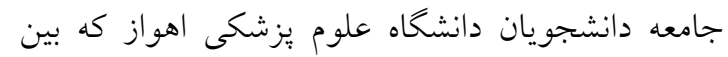
هوش هيجانى و وضعيت تأهل رابطهاى يافت نكردند،

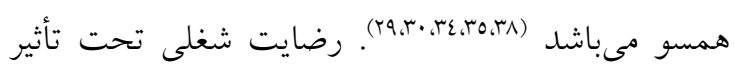
متغيرهاى متعددى است كه اين متغيرها نيز به فراخور

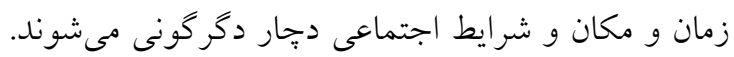

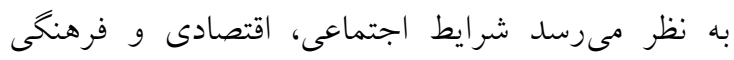
حاكم بر جامعه به ميزان زيادى تعيين كننده عوامل مؤثر 


\section{References}

1. Song LJ, Huang GH, Peng KZ, Law KS, Wong CS, Chen Z. The differential effects of general mental ability and emotional intelligence on academic performance and social interactions. Intelligence. 2010;38(1):137-43.

2. Cherniss C. Emotional intelligence: New insights and further clarifications. Ind Organ Psychol. 2010;3(2):183-91.

3. Akbarizadeh F, Bagheri F, Hatami HR, Hajivandi A. Relationship between Nurses' Spiritual Intelligence with Hardiness and General Health. Journal Of Kermanshah University Of Medical Sciences (Behbood). 2012;15(6):466-72. [Persian]

4. Slaski M, Cartwright S. Health, performance and emotional intelligence: An exploratory study of retail managers. Stress Health. 2002;18(2):63-8.

5. Heidari Tafreshi GH.H., Delfan Azari GH.A. Study of the Relationship between Students' Emotional Intelligence and Their Skills of Dealing with Stress. Ducational Administration Research Quarterly. 2011;2(2):15-24. [Persian]

6. Habibpor Z, Khorami Markani A. Emotional intelligence and its application in nursing. J Urmia Nurs Midwifery Fac. 2005;3(4):156-66. [Persian]

7. Por J, Barriball L, Fitzpatrick J, Roberts J. Emotional intelligence: Its relationship to stress, coping, well-being and professional performance in nursing students. Nurse Educ Today. 2011;31(8):855-60.

8. Saatchi M. Applicational psychology for managers in home, school and organization. Tehran1995 [Persian]. 1995.

9. Applebaum D, Fowler S, Fiedler N, Osinubi O, Robson M. The impact of environmental factors on nursing stress, job satisfaction, and turnover intention. The Journal of nursing administration. 2010;40:323.

10. Spector PE. Measurement of human service staff satisfaction: Development of the Job Satisfaction Survey. Am J Community Psychol. 1985;13(6):693.

11. Asghari e, Khaleghdoust T, Asgari F, Kazemnejad E. Effective Factors on Nurses' Job Satisfaction. Journal Of Holistic Nursing And Midwifery. 2010;20(64):1-7. [Persian]

12. Nabirye RC, Brown KC, Pryor ER, Maples EH. Occupational stress, job satisfaction and job performance among hospital nurses in Kampala, Uganda. Journal of nursing management. 2011;19(6):760-8.

13. Ganji-Arjenaki M, Dalvi MR. The Impact of ethical leadership on job stress and occupation turnover intention in nurses of hospitals affiliated to Shahrekord University of Medical Sciences. Journal of Shahrekord Uuniversity of Medical Sciences. 2014;16. [Persian]

14. Ziapour A. An investigation of the job satisfaction and related factors in nurses of Kermanshah hospitals. JPSR. 2013;2(2):27-34.

15. Al Maqbali MA. Factors that influence nurses' job satisfaction: a literature review. Nursing management. 2015;22(2).

16. Rosta J, Nylenna M, Aasland OG. Job satisfaction among hospital doctors in Norway and Germany. A comparative study on national samples. Scand J Public Health. 2009;37(5):503-8.

17. Moosavi Tabar S.Y, Rahmani R, Sirati Nayyer M, Abbas Zadeh Z. Influence factors in job satisfaction of nurses in the selected military and civil hospital in Tehran; 2013. Journal of Nurse And Physician Within War. 2013;(23-24):34-9. [Persian]

18. Madanipour N, Mohagheghiyan SH, Rahimi M, Sayadi A. An Investigation of the Relationship between Job Satisfaction and Emotional Intelligence among Isfahan State Hospital's Nurses. Journal of Torbat Heydariyeh University of Medical Sciences. 2013;1(2):63-9. [Persian]

19. Jafar Jalal E, Joolaee S, Hajibabaee F, Bahrani N. Evaluating the relationship between nurses' occupational satisfaction and patients' satisfaction with nursing service. Iranian Journal of Nursing Research. 2015;10(1):25-34. [Persian]

20. Lu H, Barriball KL, Zhang X, While AE. Job satisfaction among hospital nurses revisited: a systematic review. Int J Nurs Stud. 2012;49(8):1017-38.

21. Darvish H, Shabani F, Ghasempuor R. The Survey of the Relationship between Emotional Intelligence, Self-Efficiency \& Job Satisfaction: A Case Study at Educational and Medical Centers in Tabriz Province. Advances In Nursing And Midwifery (Faculty Of Nursing Of Midwifery Quarterly) . 2012;21(75):53-81. [Persian] 
22. Farzadnia F. The Impact of Emotional Intelligence on conflict-handling styles among the head nurses of Milad hospital, Tehran. Journal of Ilam University of Medical Sciences. 2012;20(2):5361. [Persian]

23. Lane AM, Meyer BB, Devonport TJ, Davies KA, Thelwell R, Gill GS, Diehl CD, Wilson M, Weston N. Validity of the emotional intelligence scale for use in sport. J Sports Sci Med. 2009;8(2):289.

24. Rostami M, Movaghari MR, Taghavi T, Mehran A. The relationship between emotional intelligence and coping styles of nurses in hospitals in Kermanshah University of Medical Sciences. Iranian Journal of Nursing Research. 2016;11(1):51-61. [Persian]

25. Safarinia M, Solgi Z, Tavakkoli S. Investigating validity and reliability of social Intelligence Questionnaire Among university students in Kermanshah. 2011. [Persian]

26. Tavan A, Chehrzad M, Kazemnejad Leili E, Sedri N. Relationship between emotional intelligence and occupational exhaustion on nurses. Journal of Holistic Nursing And Midwifery. 2016;26(2):49-58. [Persian]

27. Akbaritabar AA, Mokarami H, Nazifi M, Rahi A, Mirkamandar EH, Hosseinpouri ME. Psychometric properties of Spector's job satisfaction survey in the Iranian population. Koomesh. 2013;14(3):335-41. [Persian]

28. Etebarian A, Omidpanah A. The relation between the emotional intelligence and job satisfaction. 2008. [Persian]

29. Hannani S, Khaneghah ZN, Sadati L, Asl MF. Relationship between Emotional Intelligence and Coping-With-Stress Styles in Operating Room Technologists. Iranian Journal of Nursing Research. 2018;13(3):19-26. [Persian]

30. Akbari H, Akbari H, Mohammadian M. Nurse job satisfaction compared with healthcare personnel: A cause cross sectional study. Health Research Journal. 2016;1(1):33-41. [Persian]

31. Choobineh A, Shahcheragh B, Keshavarzi S, Rahnama K. Shift work-related problems among operation room technicians of Shiraz University of Medical Sciences hospitals, 2006-2007. Iran Occupational Health. 2007;4(1):48-52. [Persian]

32. Utriainen K, Kyngäs H. Hospital nurses' job satisfaction: a literature review. Journal of nursing management. 2009;17(8):1002-10.

33. Landa JM, López-Zafra E, Martos MP, del Carmen Aguilar-Luzon M. The relationship between emotional intelligence, occupational stress and health in nurses: a questionnaire survey. Int $J$ Nurs Stud. 2008;45(6):888-901.

34. Delpasand M, Nasiripoor AA, Raiisi P, Shahabi M. The relationship between emotional intelligence and occupational burnout among nurses in critical care units. Iranian journal of critical care nursing. 2011;4(2):79-86. [Persian]

35. Ghaderi M, Shamsi A. The correlation between emotional intelligence and mental health among students of Jiroft city. 2016. [Persian]

36. Biranvand N, Komili H, Heydari H. Survey relationship between emotional intelligence and coping strategies to stress in nurses. Journal of Clinical Nursing and Midwifery. 2015;4. [Persian]

37. Park HS, Ha JH, Lee MH, Lee HJ. The relationship between emotional intelligence and stress coping of nurses. J Korean Acad Fundam Nurs. 2014;21(4):466.

38. Ghaderi M, Nasiri M, Zakeri Y, KhedriMeirghaidi R. Assessment of emotional intelligence in Ahvaz Universities students in 2014. Journal of Rafsanjan University of Medical Sciences. 2015;14(5):379-92. [Persian] 